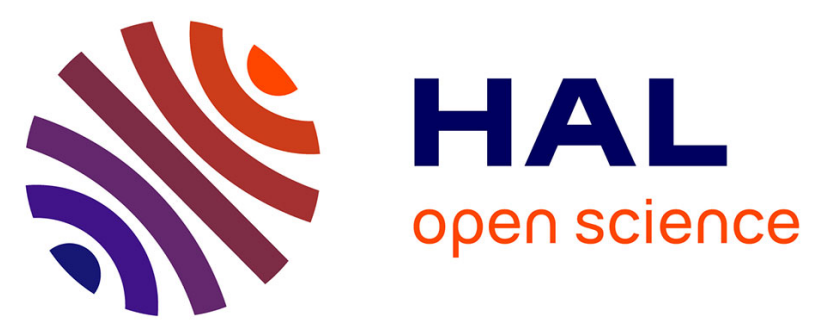

\title{
Selective Hydrosilylation of Esters to Aldehydes Catalysed by Iridium(III) Metallacycles through Trapping of Transient Silyl Cations
}

Yann Corre, Vincent Rysak, Frédéric Capet, Jean-Pierre Djukic, Francine Agbossou-Niedercorn, Christophe Michon

\section{To cite this version:}

Yann Corre, Vincent Rysak, Frédéric Capet, Jean-Pierre Djukic, Francine Agbossou-Niedercorn, et al.. Selective Hydrosilylation of Esters to Aldehydes Catalysed by Iridium(III) Metallacycles through Trapping of Transient Silyl Cations. Chemistry - A European Journal, 2016, 22 (39), pp.14036 14041. 10.1002/chem.201602867. hal-01715059

\section{HAL Id: hal-01715059 \\ https://hal.science/hal-01715059}

Submitted on 2 Jan 2022

HAL is a multi-disciplinary open access archive for the deposit and dissemination of scientific research documents, whether they are published or not. The documents may come from teaching and research institutions in France or abroad, or from public or private research centers.
L'archive ouverte pluridisciplinaire HAL, est destinée au dépôt et à la diffusion de documents scientifiques de niveau recherche, publiés ou non, émanant des établissements d'enseignement et de recherche français ou étrangers, des laboratoires publics ou privés. 


\title{
Selective hydrosilylation of esters to aldehydes catalysed by iridium(III) metallacycles through trapping of
}

\author{
transient silyl cations.
}

\author{
Yann Corre, ${ }^{[a, b]}$ Vincent Rysak, ${ }^{[a, b]}$ Frédéric Capet, ${ }^{[a]}$ Jean-Pierre Djukic, ${ }^{[c]}$ Francine Agbossou- \\ Niedercorn ${ }^{*[a, b]}$ and Christophe Michon*[a,b]
}

\begin{abstract}
The combination of an iridium(III) metallacycle and 1,3,5-trimethoxybenzene catalyses rapidly and selectively the reduction of esters to aldehydes at room temperature with high yields through hydrosilylation followed by hydrolysis. The ester reduction involves the trapping of transient silyl cations by the 1,3,5-trimethoxybenzene co-catalyst supposedly by formation of an arenium intermediate which role was addressed by DFT calculations.
\end{abstract}

\section{Introduction}

Aldehydes are important molecules in organic chemistry. Three main synthetic pathways can achieve their preparation starting from widely available chemicals: the hydroformylation of olefins ${ }^{[1]}$ the oxidation of primary alcohols ${ }^{[2]}$ and the reduction of carboxylic acid derivatives. ${ }^{[3]}$ However, because of the aldehyde reactivity, chemoselectivity issues may be encountered. If the single reduction of esters to aldehydes is possible using diisobutylaluminum hydride (DIBAL-H) or lithium tri-tertbutoxyaluminum hydride, these reagents are not used regularly on high scales because of their sensitivity and capricious reputation. ${ }^{[4]}$ Alternatively, the use of hydrosilanes as reductants is an area of growing interest for the mild and selective reduction of carboxylic acid derivatives using transition metal or Lewis acid catalysts. ${ }^{[5]}$ Indeed, this strategy enables the formation of silylacetals which can be converted to aldehydes upon hydrolysis. If the hydrosilylation reaction has been successful for the selective reduction of esters to alcohols or ethers, ${ }^{[6,7]}$ examples of hydrosilylation of esters to aldehydes are scarce. ${ }^{[8]}$ A first example has demonstrated a rather narrow substrate scope using a ruthenium carbonyl catalyst at high temperature. ${ }^{[8 a]}$ A second method has applied a catalyst based on $\mathrm{Pd}(\mathrm{OAc})_{2}$ and triphenylphosphine for the exclusive reduction of 2-pyridinyl esters. ${ }^{[8 b]}$ The strong organoborane Lewis acid $\mathrm{B}\left(\mathrm{C}_{6} \mathrm{~F}_{5}\right)_{3}$ catalyses efficiently the hydrosilylation of esters with triphenylsilane to afford silyl acetals along with the overreduction products silyl ethers and alkanes. ${ }^{\left[{ }^{[c]}\right]}$ More recently, the synthesis of aldehydes via ester hydrosilylation and hydrolysis of the resulting silyl acetals was performed independently by

[a] Dr. Y. Corre, V. Rysak, Dr. F. Capet, Dr. F. Agbossou-Niedercorn, Dr. C. Michon, Univ. Lille, CNRS, Centrale Lille, ENSCL, Univ. Artois, UMR 8181 - UCCS - Unité de Catalyse et Chimie du Solide, F-59000 Lille, France. E-mail: christophe.michon@ensc-lille.fr, francine.agbossou@ensc-lille.fr

[b] ENSCL, UCCS-CCM-CASECO, (Chimie-C7) CS 90108, 59652 Villeneuve d'Ascq Cedex, France

[c] Dr. J.-P. Djukic, Institut de Chimie de Strasbourg, UMR 7177 , Université de Strasbourg, 4 rue Blaise Pascal, F-67000 Strasbourg, France.

Supporting information for this article is available free of charges on the web

Brookhart et al. and Darcel et al. ${ }^{[8 \mathrm{~d}-\mathrm{e}]}$ The former has combined
0.1-0.5 mol\% of $\left[\operatorname{Ir}(\text { cyclooctene })_{2} \mathrm{Cl}\right]_{2}$ catalyst and an excess of diethylsilane to reduce a broad scope of substrates in high yields at temperatures from ambient to $50^{\circ} \mathrm{C}$. ${ }^{[8 d]}$ The latter has developed $\mathrm{N}$-heterocyclic-carbene-ironcarbonyl catalysts for the hydrosilylation of aromatic and aliphatic esters at $1 \mathrm{~mol} \%$ catalyst loading, in the presence of a slight excess of diethylsilane or diphenylsilane and under UV irradiation at room temperature. ${ }^{[8 e]}$ Besides these significant achievements, our attention was drawn by the seminal work of Nagashima et al. who, after a study on ruthenium catalysed selective reduction of esters to alcohols and ethers, ${ }^{[9 a]}$ reported on primary alkylation of electron enriched aromatic compounds with esters using a ruthenium catalyst and a silane reagent (Scheme 1). . $^{[9 b-c]}$ Along our studies on hydrosilylation reactions of carbon-heteroatom insaturations, ${ }^{[10]}$ we have observed an original reactivity while using 1,3,5-trimethoxybenzene (TMB) in combination with other catalysts and silane reagents. Herein, we report on the selective hydrosilylation of esters into aldehydes catalysed by an $\operatorname{Ir}(\mathrm{III})$ cyclometallated complex and 1,3,5-trimethoxybenzene at room temperature.

Primary alkylation of aromatics with esters by Nagashima et al.<smiles>[R]C(=O)O[18F]</smiles>

This work: hydrosilylation of esters to aldehydes 13 examples

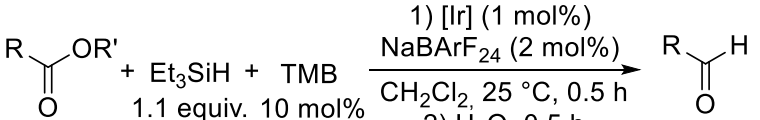

$$
\begin{aligned}
& \text { 2) } \mathrm{H}_{2} \mathrm{O}, 0.5 \mathrm{~h} \quad 54-99 \% \text { yield } \\
& 18 \text { examples }
\end{aligned}
$$

$\mathrm{NaBArF}_{24}=$ sodium tetrakis[(3,5-trifluoromethyl)phenyl]borate

Scheme 1. Esters in alkylation and hydrosilylation reactions.

\section{Results and Discussion}

Following our previous investigations on $\operatorname{Ir}(\mathrm{III})$ metallacycles as catalysts for the hydrosilylation of imines, ${ }^{[10]}$ we started studying the hydrosilylation of ethyl ester $\mathbf{3 a}$ using triethylsilane without any further hydrolysis (Table 1). Interestingly, a catalyst loading of $1 \mathrm{~mol} \%$ of iridacycle 1 and a $\mathrm{NaBArF}_{24}$ additive of $2 \mathrm{~mol} \%$ proved to lead selectively to silylacetal $\mathbf{4 a}$ in a $58 \%$ yield but an additional time lapse didn't allow the reaction to reach completion (entry 1). Surprisingly, under similar reaction conditions, the use of iridacycle 2 in combination with $\mathrm{NaBArF}_{24}$ led to a mixture of three products, ethyl- and silyl-ether, $\mathbf{5 a}$ and $\mathbf{6 a}$, being the major ones and silylacetal $\mathbf{4 a}$ the minor (overall yield $48 \%$ ) (entry 2). It was worth noting the addition of 3 equivalents of triethylsilane afforded mainly 5 a (68\%) along with $6 \mathbf{a}(32 \%)$ and $4 \mathbf{a}(14 \%)$ in an overall quantitative yield (entry 3 ). When 3 equivalents of triethylsilane were used with iridacycle $\mathbf{1}$, we obtained $\mathbf{4 a}$ as the major product (75\%) with some ethyl- and silyl-ether, 5a (19\%) and 6a 
$(6 \%)$, the overall yield being quantitative (entry 4$)$. While using $2 \mathrm{~mol} \%$ of tritylBArF ${ }_{20}$.additive, ethyl-ether $\mathbf{5 a}$ was the main product formed in 53-44\% overall yields (entries 5,6 ). This trend may be explained by the propensity of trityl cation to interact with silyl-ether group and allow its elimination.

Table 1. Catalytic study.

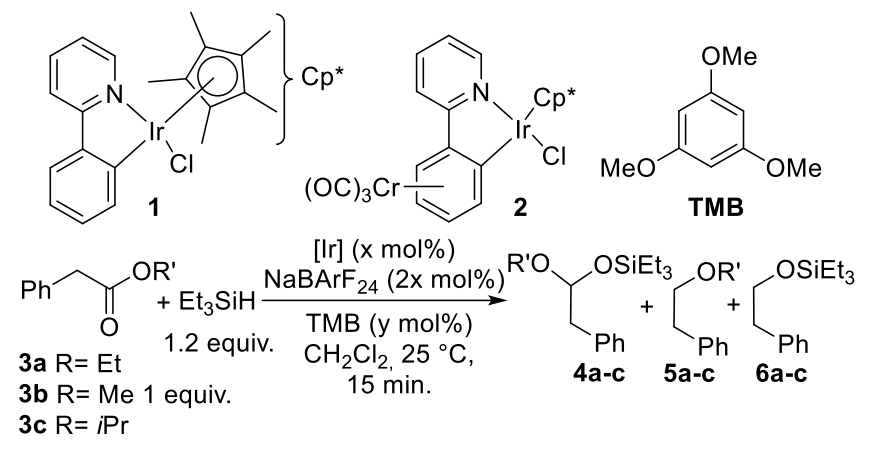

\begin{tabular}{|c|c|c|c|c|c|c|c|}
\hline Entry & 3 & $\begin{array}{c}{[\mathrm{Ir}]} \\
(\mathrm{mol} \%)\end{array}$ & $\begin{array}{l}\text { TMB } \\
(\mathrm{mol} \%)\end{array}$ & $\begin{array}{l}\text { Yield } \\
(\%)^{[a]}\end{array}$ & \multicolumn{3}{|c|}{$\begin{array}{c}\text { Selectivity }{ }^{[a]} \\
\text { 4a-c / 5a-c / 6a-c }\end{array}$} \\
\hline $1^{[\mathrm{b}]}$ & $3 a$ & $1(1)$ & 0 & 58 & 100 & 0 & 0 \\
\hline 2 & $3 a$ & $2(1)$ & 0 & 48 & 17 & 54 & 29 \\
\hline $3^{[c]}$ & $3 a$ & $2(1)$ & 0 & 100 & 14 & 68 & 32 \\
\hline $4^{[c]}$ & $3 a$ & 1 (1) & 0 & 100 & 75 & 19 & 6 \\
\hline $5^{[\mathrm{d}]}$ & $3 a$ & $1(1)$ & 0 & 53 & 0 & 84 & 16 \\
\hline $6^{[d]}$ & $3 a$ & $2(1)$ & 0 & 44 & 0 & 85 & 15 \\
\hline 7 & $3 a$ & $2(1)$ & 100 & 100 & 100 & 0 & 0 \\
\hline $8^{[e]}$ & $3 a$ & $2(1)$ & 1 & 63 & 83 & 17 & tr. \\
\hline $9^{[e]}$ & $3 a$ & $2(1)$ & 5 & 71 & 68 & 32 & tr. \\
\hline 10 & $3 a$ & $2(1)$ & 10 & 100 & 100 & 0 & 0 \\
\hline 11 & $3 a$ & $1(1)$ & 10 & 89 & 100 & 0 & 0 \\
\hline $12^{[f]}$ & $3 a$ & $2(0.1)$ & 10 & 17 & 100 & 0 & 0 \\
\hline 13 & $3 a$ & - & 10 & 0 & - & - & - \\
\hline $14^{[\mathrm{g}]}$ & $3 a$ & 2(1) & 10 & 62 & 100 & 0 & 0 \\
\hline $15^{[\mathrm{c}]}$ & $3 a$ & $2(1)$ & 10 & 100 & 60 & 35 & 5 \\
\hline $16^{[\mathrm{h}]}$ & $3 a$ & $2(1)$ & 10 & 65 & 18 & 23 & 59 \\
\hline $17^{[\mathrm{e}]}$ & $3 b$ & 2 (1) & 10 & 53 & 30 & 70 & tr. \\
\hline 18 & $3 c$ & $2(1)$ & 10 & 100 & 100 & 0 & 0 \\
\hline
\end{tabular}

[a] Determined by ${ }^{1} \mathrm{H}$ NMR. [b] $68 \%$ yield in 24 hours. [c] Reaction with 3 equivalents of triethylsilane. [d] 2 mol\% $\mathrm{C}(\mathrm{Ph})_{3} \mathrm{BArF}_{20}$. [e] tr. = traces. [f] $22 \%$ in 2 hours. [g] 1 equiv. $\mathrm{Et}_{3} \mathrm{SiH}$. [h] 1.2 equiv. of $1,1,3,3$ tetramethyldisiloxane (TMDS).

In an attempt to adjust the silane reactivity, several ether additives were tested (see table S1 in the Supplementary Information). We noticed the use of one equivalent of 1,3,5trimethoxybenzene (TMB) led to the quantitative synthesis of silylacetal $4 a$ (entry 7 ). Though 1 or $5 \mathrm{~mol} \%$ of TMB implied the formation of product $4 \mathbf{a}$ with some ethyl ether $5 \mathrm{a}$ in lower overall yields (entries 8-9), a 10 mol\% TMB loading afforded again selectively silylacetal $\mathbf{4 a}$ in a quantitative yield (entry 10). Within these reaction conditions, iridacycle 1 led to a less efficient catalyst (entry 11) and a $0.1 \mathrm{~mol} \%$ loading of complex 2 resulted in low yields independently of the reaction time (entry 12). The presence of an $\operatorname{Ir}(\mathrm{III})$ metallacycle proved to be critical to allow the hydrosilylation of ester 3a (entry 13). Furthermore, the use of 1.2 equivalents of triethylsilane proved to be essential to reach a full conversion (entries 14, 15). In the presence of TMB, the addition of 3 equivalents of triethylsilane allowed the formation of $\mathbf{4 a}$ with some ethyl- and silyl-ether products, $\mathbf{5 a}$ and $6 a$ in a $60 / 35 / 5$ ratio (entry 15). The substitution of triethylsilane for 1,1,3,3-tetramethyldisiloxane (TMDS) implied lower yield and selectivity (entry 16). Finally, we noticed the hydrosilylation reaction was sensitive to the nature of the ester function. Indeed, methyl ester $\mathbf{3 b}$, a weaker electron-donating group, led mainly to methylether $\mathbf{5 b}$ along with some silylacetal $\mathbf{4 b}$ ( $7 / 3$ ratio) in a modest yield (entry 17). By comparison, ester $3 \mathbf{c}$ bearing an electron-rich isopropyl substituent, afforded selectively silylacetal $\mathbf{4 c}$ in a quantitative yield (entry 18).

The reaction scope was studied with the hydrosilylation of a series of aromatic and aliphatic esters under the optimized conditions determined above (Scheme 2). It was worth noting the hydrolysis of the resulting silylacetals into the corresponding aldehydes could be performed in most cases through a simple addition of water to the reaction mixture. Indeed, the hydration of the remaining additive $\mathrm{NaBArF}_{24}$ resulted in a catalysis producing a Brønsted acid which could cleave chemoselectively the generated silylacetals. ${ }^{[11]}$ As already stated, methyl 2-phenylacetate $\mathbf{3 b}$ led to the corresponding aldehyde with a moderate yield and the hydrosilylation of phenyacetates $\mathbf{3 a}$ and $\mathbf{3 c}$ could be performed readily. Reagent 3d bearing a 2-phenylpropanoate skeleton was also reduced selectively without any effect of the substrate's steric hindrance. Though the hydrosilylation of ester $3 \mathbf{e}$ based on a furan heterocycle was straightforward, the reduction of the thiophene based ester $\mathbf{3 f}$ proved to be more challenging and led only to the corresponding acetal. ${ }^{[12]}$ We noticed the hydrosilylation of benzyl benzoate $3 \mathrm{~m}$ and related ortho- and para- substituted esters $\mathbf{3 g}-\mathbf{k}, \mathbf{3 n}$ proceeded selectively to the desired aldehydes in high yields independently of the reagent substitution pattern. However, ortho- substitution by a methoxy group led to an unreactive substrate 3 I which probably binds to the catalyst as a strong chelate. Finally, linear and cyclic aliphatic esters 30-s were reduced selectively to the corresponding aldehydes in high yields at the exception of ester $\mathbf{3 q}$ whose resulting acetal could not be hydrolyzed. ${ }^{[12]}$

Regarding the reaction mechanism, pre-catalyst 2 is first dehalogenated by $\mathrm{NaBArF}_{24}$ to lead to transient cationic complex 8 (Scheme 3). ${ }^{[10 b]}$ The iridium catalyst shall activate the triethylsilane through the formation of silane-iridium adduct 9. ${ }^{[13,14]}$ Such an activation process would produce an iridium hydride complex $\mathbf{1 0}^{[10 a, 15]}$ and a triethylsilyl cation. ${ }^{[16]}$ The latter may activate the carbonyl of the ester substrate $\mathbf{3}$ and generate a silyloxy-carbonium which is stabilized by the electron-donating group R'. Reaction with a first equivalent of the iridium hydride complex 10 affords the silyl acetal 4 along with the cationic iridium catalytic species $\mathbf{8}$. At this stage, the generation of the iridium hydride complex 10 and the triethylsilyl cation seems 

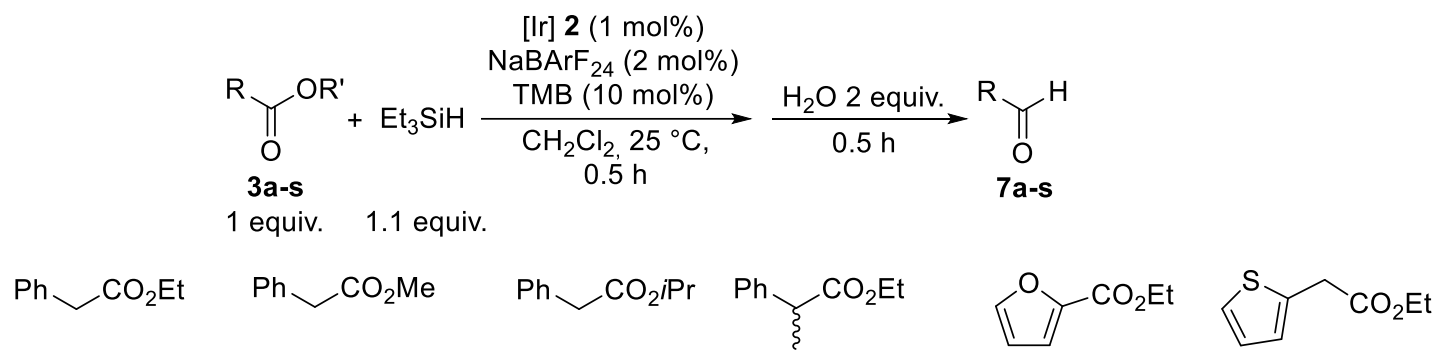

3a $100 \%$ yield $^{[a]} \quad$ 3b $53 \%(-) \quad$ 3c $100 \%(-) \quad$ 3d $100 \%(64 \%)^{[b]} \quad$ 3e $100 \%(95 \%) \quad$ 3f $54 \%(41 \%)^{[d]}$ $(99 \% \text { isolated yield })^{[b]}$<smiles>CCOC(=O)c1ccc(Cl)cc1</smiles>

3g $100 \%$ (66\%)<smiles>CCOC(=O)c1ccccc1Cl</smiles>

3h $100 \%$ (98\%)<smiles>CCOC(=O)c1ccc(C)cc1</smiles>

3i $100 \%(69 \%)$<smiles>CCOC(=O)c1ccccc1C</smiles>

3j $100 \%(75 \%)$<smiles>CCOC(=O)c1ccc(OC)cc1</smiles>

3k $100 \%(89 \%)$<smiles>CCOC(=O)c1ccccc1OC</smiles><smiles>O=C(OBr)c1ccccc1</smiles><smiles>CCOC(=O)CCc1ccc(C(=O)OCC)cc1</smiles>

3n $100 \%(74 \%)^{[c]}$ 3o $100 \%(68 \%)^{[b]}$ 3p $100 \%(75 \%)$ 3q $100 \%(59 \%)^{[d]}$ 3r $85 \%(70 \%)$

3s $100 \%(40 \%)$

[a] yields measured by ${ }^{1} \mathrm{H}$ NMR (isolated yields). [b] isolated as the 2,4-dinitrophenylhydrazone adduct. [c] 2.2 equiv. Ets $\mathrm{SiH}$ used and product hydrolysed with 4 equiv. $\mathrm{H}_{2} \mathrm{O}$. [d] isolated as the resulting acetal; no hydrolysis observed with $\mathrm{HCl}(2 \mathrm{M})$ or $\mathrm{NaOH}(2 \mathrm{M})$ in $\mathrm{THF}$.

Scheme 2. Reaction scope.

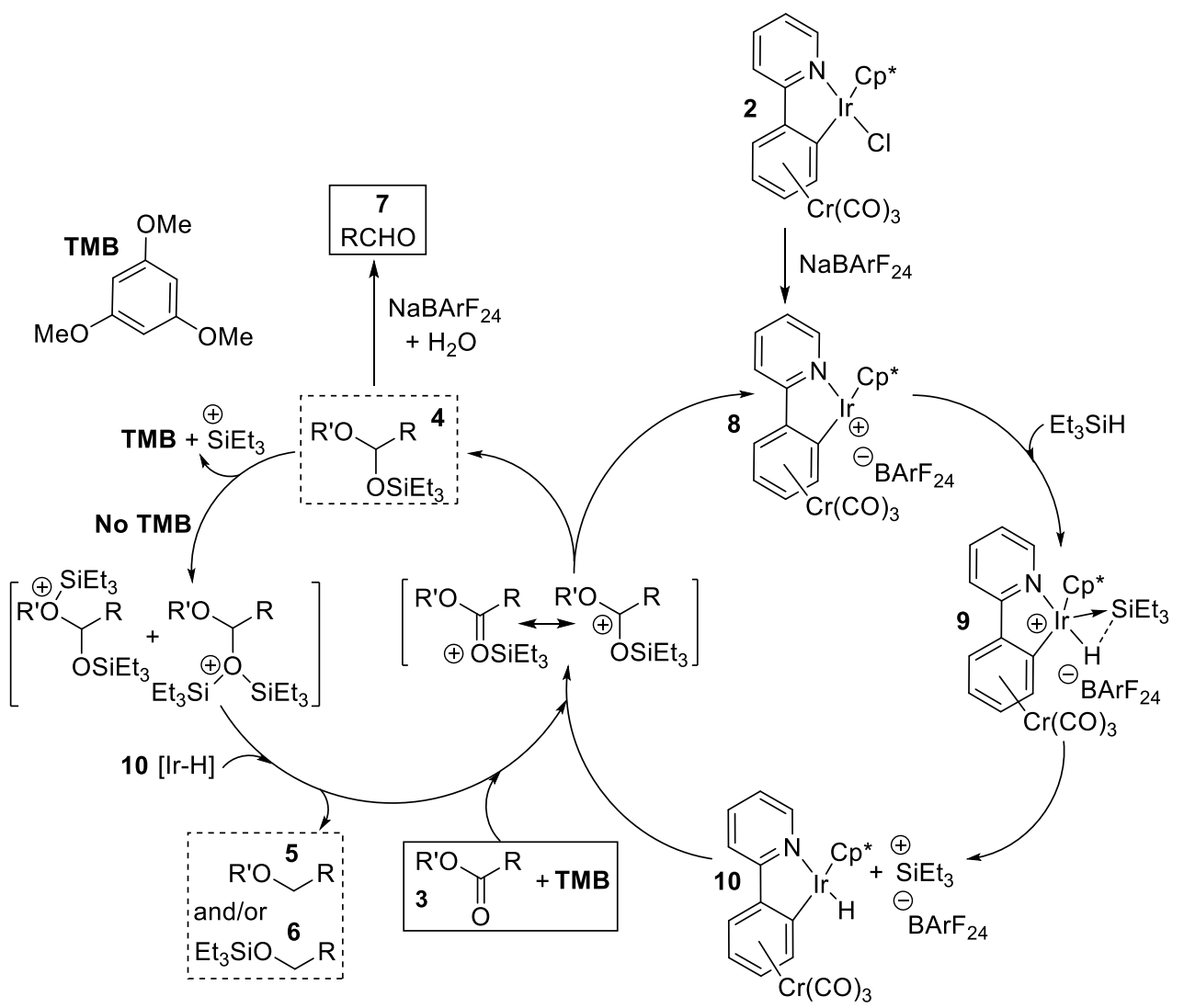

Scheme 3. Reaction mechanism proposal. 


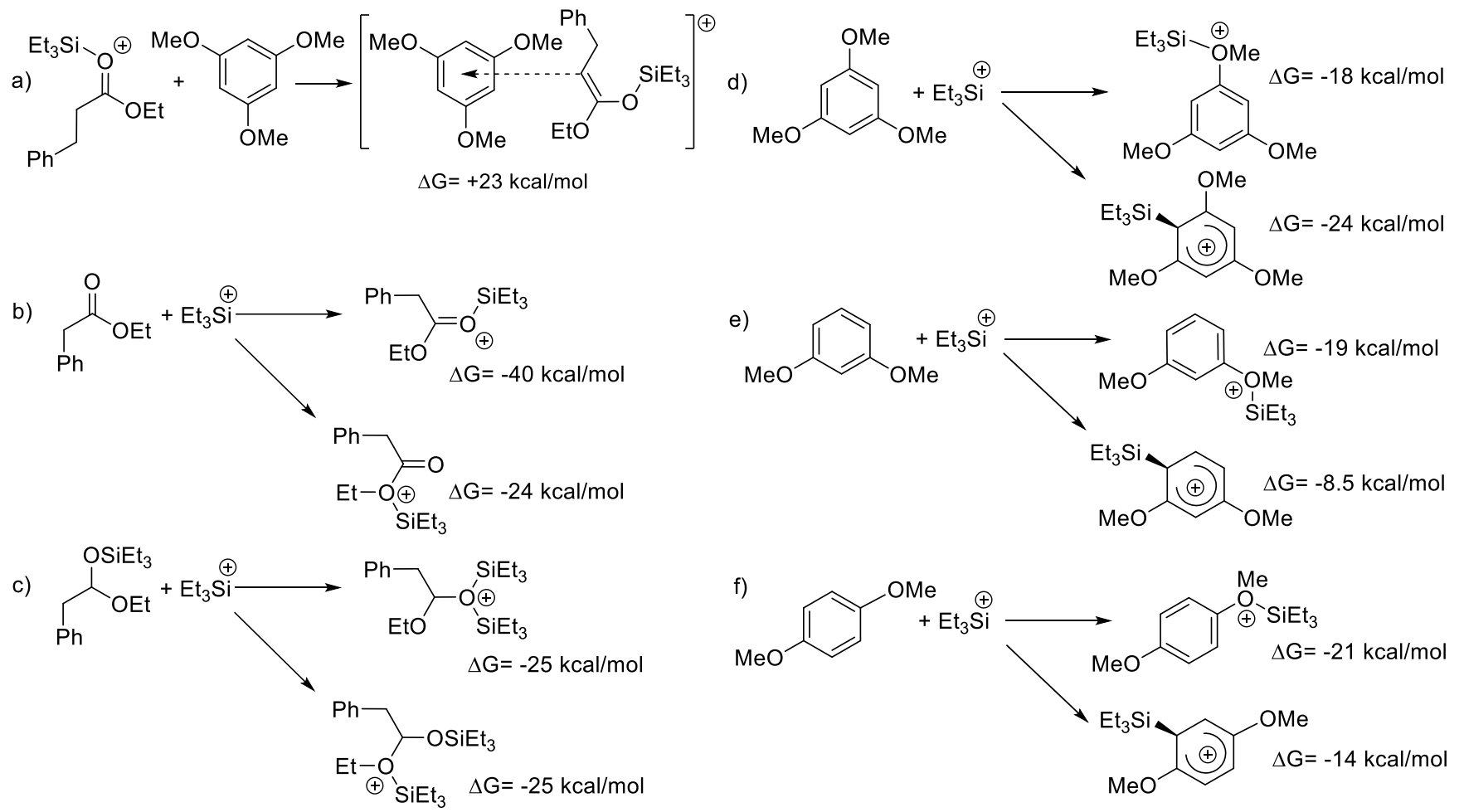

Figure 1. DFT-D (ZORA-PBE-D3(BJ)/all electron TZP) calculated thermochemistries with COSMO solvation $\left(\mathrm{CH}_{2} \mathrm{Cl}_{2}, \mathrm{~T}=298.15 \mathrm{~K}\right)$.

faster than the synthesis of silyl acetal $\mathbf{4}$ and release of species 8. Indeed, we observed alkylether 5 and silylether 6 were the major reaction products with respect to $\mathbf{4}$ when no $1,3,5$ trimethoxybenzene was used as co-catalyst (Table 1, entry 2). Hence, 1,3,5-trimethoxybenzene would trap the remaining triethylsilyl cation probably through an aromatic electrophilic substitution generating a Si-C arenium (Wheland type) intermediate. ${ }^{[16]} \mathrm{A}$ final hydrolysis of the silyl acetal $\mathbf{4}$ is catalysed after hydration of the remaining $\mathrm{NaBArF}_{24}$ additive ${ }^{[11]}$ and offers the desired aldehyde product while the Si-C Wheland intermediate would probably be involved in the reduction of another molecule of ester 3. Without 1,3,5-trimethoxybenzene, the silyl acetal 4 reacts further through activation of its ether groups by triethylsilyl cation. This affords after reaction with a second equivalent of iridium hydride complex $\mathbf{1 0}$ the alkylether 5 and silylether $\mathbf{6}$ as well as the catalytic cationic iridium species $\mathbf{8}$. This second pathway was confirmed by some experimental results. First, when a great excess of triethylsilane was used (3 eq.), the synthesis of ethers $5 \mathbf{a}$ and $6 \mathbf{a}$ was almost quantitative (Table 1, entry 3 ). In addition, the combined use of iridium precursor, [trityl] $\left[\mathrm{BArF}_{20}\right]$ additive and triethylsilane led mainly to ethyl-ether $5 \mathrm{a}$ in $44-53 \%$ yields (Table 1 , entries 5,6 ). This confirmed the propensity of strong electrophiles like triethylsilyl and trityl cations to eliminate ether groups and form products 5 and 6 (Scheme 3). In such a case, it was likely average yields could only be obtained while 1.2 equivalents of triethylsilane were used, 2 equivalents of iridium hydride complex 10 being required for that pathway.

In order to further confirm the proposed reaction mechanism, the role of 1,3,5-trimethoxybenzene in the trapping of triethylsilyl cation was studied from a broad prospect. Not considering in a first instance the actual kinetic aspects of the transfer of the silylium cation $\mathrm{Et}_{3} \mathrm{Si}^{+}$, we focused on the thermochemistry of its interaction particularly with the arene additive as well as with the various organic molecules involved in the catalysis. First, it must be noted that possible interaction of the silyliumactivated ester cation with 1,3,5-trimethoxybenzene was found highly unfavored (Figure $1 \mathrm{a}$ and Figure S2). Conventional COSMO $\left(\mathrm{CH}_{2} \mathrm{Cl}_{2}\right) / \mathrm{DFT}-\mathrm{D}$ computation of the Gibbs enthalpy of the reaction depicted in Figure 1a for a model reaction, including or not the $\mathrm{BArF}_{24}$ anion, produced an endoergonic value of around $+23 \mathrm{kcal} / \mathrm{mol}$ which cleared doubts about a possible interaction of intermediate carbocationic species with the arene additive. Figure $1 \mathrm{~b}-\mathrm{f}$ depicts the possible scenarios of addition of the silylium cation $\mathrm{Et}_{3} \mathrm{Si}^{+}$to the ester $\mathrm{PhCH}_{2} \mathrm{C}(\mathrm{O}) \mathrm{OEt}$, the acetal $\mathrm{PhCH}_{2} \mathrm{C}\left(\mathrm{OSiEt}_{3}\right)(\mathrm{OEt}), \quad$ 1,3,5-trimethoxybenzene, 1,3dimethoxybenzene and 1,4-dimethoxybenzene. On thermochemical grounds, the addition of the silylium cation at the carbonyl's oxygen atom is greatly favored over other competing interactions with the arene additive, which are disfavored by ca. $16 \mathrm{kcal} / \mathrm{mol}$ for 1,3,5-trimethoxybenzene. It is therefore likely that the first step of the catalysis that entails the reduction of the ester into the acetal does not necessarily imply explicitly the arene additive. The latter's interaction with $\mathrm{Et}_{3} \mathrm{Si}^{+}$tends to be more critical in the second step where the acetal undergoes a reduction into an ether. In this case, the silylium cation has an affinity for 1,3,5-trimethoxybenzene of $-24 \mathrm{kcal} / \mathrm{mol}$ for a reaction affording a typical Si-C Wheland intermediate; the Obinding of $\mathrm{Et}_{3} \mathrm{Si}^{+}$being disfavored by ca. $6 \mathrm{kcal} / \mathrm{mol}$ (Figures $1 \mathrm{~d}$ and 2). The fact that the affinities of the silylium cation for the acetal and for 1,3,5-trimethoxybenzene are almost equal within $1 \mathrm{kcal} / \mathrm{mol}$ may explain the minimal conversion of the acetal into ethers in the course of the catalysis. In this case, we hypothesize that 1,3,5-trimethoxybenzene moderates the electrophilicity of $\mathrm{Et}_{3} \mathrm{Si}^{+}$by dragging it into an equally probable interaction with the arene, with a possible subsequent formation of a silylated TMB and release of $\mathrm{H}^{+}$ which would be detrimental to the hydrido-iridium catalytic species and would cause the end of the catalysis. The affinity of $\mathrm{Et}_{3} \mathrm{Si}^{+}$for the other two dimethoxybenzene isomers is characterized by a preferential binding to the oxygen atoms, the formation of the corresponding Wheland intermediates being disfavored by ca $7-10 \mathrm{kcal} / \mathrm{mol}$. The 
affinity of the two dimethoxybenzene isomers for $\mathrm{Et}_{3} \mathrm{Si}^{+}$is overall by $3-5 \mathrm{kcal} / \mathrm{mol}$ lower than that of TMB and the diversion of $\mathrm{Et}_{3} \mathrm{Si}^{+}$by interaction could be disfavored.

a)

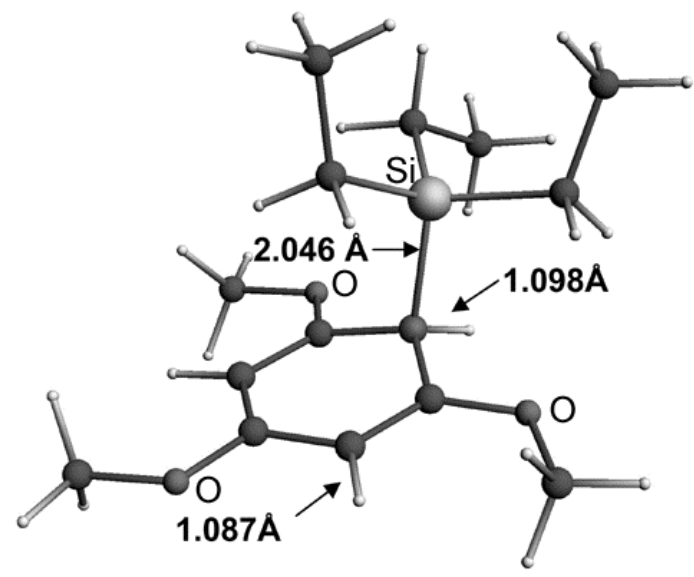

b)

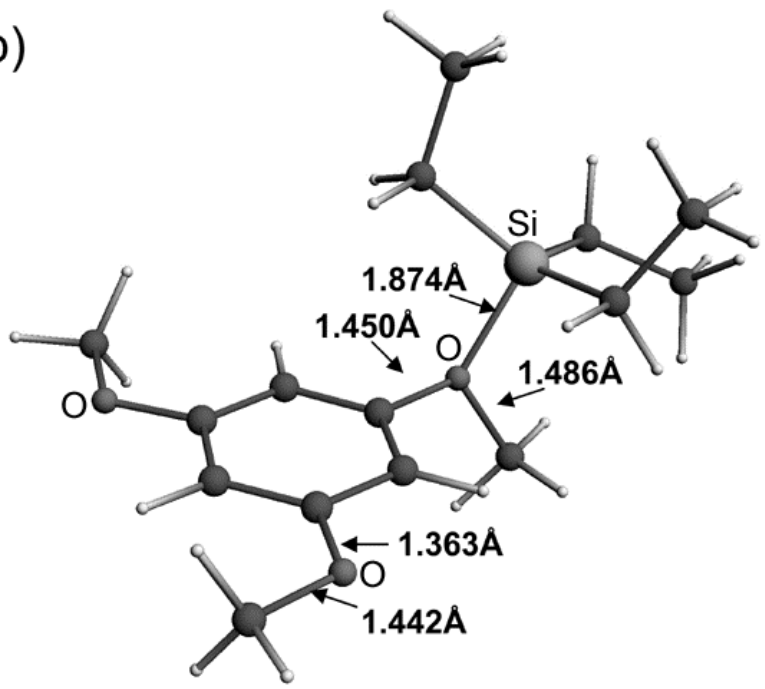

Figure 2. Gas-phase singlet ground state geometries of the cationic Wheland type adduct (a) and the O-silylium adduct resulting from the interaction of $\mathrm{Et}^{3} \mathrm{Si}^{+}$with TMB (b).

Several attempts were performed to crystallize the adduct of 1,3,5-trimethoxybenzene (TMB) and triethysilyl cation. If such compound could not be evidenced, other unrelated areniums were crystallized (see Schemes S1-S4, Figure S1 and Table S1 in the Supplementary Information).

\section{Conclusions}

To summarize, the combination of an iridium(III) cyclometallated complex and 1,3,5-trimethoxybenzene catalyses efficiently and selectively the hydrosilylation of esters to aldehydes at room temperature with high yields using triethylsilane. A further hydrolysis of the formed acetals allows, in most cases, the straightforward formation of the aldehyde. The selective ester reduction is most probably favoured by the trapping of transient silyl cations leading to an arenium intermediate which inhibits any further reductive transformation of the formed acetal. In the presence of 1,3,5-trimethoxybenzene, no further reduction of the key silyl acetal intermediate ensues and the formation of the aldehyde product is more often than not straightforward upon hydrolysis. However, in the absence of 1,3,5-trimethoxybenzene, a further dealkoxylation of the silyl acetal occurs affording alkyl- and silylether products. Our results highlight the reactivity of silanes and related intermediates can be modular depending on the substituents of the silicium atoms. In the future, we believe the reactivity of Lewis acids like carbocations ${ }^{[17]}$ may be tuned using such a methodology.

\section{Experimental Section}

\section{General Procedure for the catalysis}

In a glovebox, selected iridium(III) catalyst 2 (1 mol\%), 1,3,5-trimethoxybenzene $(10 \mathrm{~mol} \%)$ and $\mathrm{NaBArF}_{24}$ additive (2 mol\%) were introduced in a Schlenk tube. Under nitrogen, distilled ester reagent $(0.31 \mathrm{mmol}, 1 \mathrm{eq}$.) and dry dichloromethane $(2 \mathrm{~mL})$ were added followed by triethylsilane reagent $(0.34 \mathrm{mmol}, 1.1 \mathrm{eq}$.$) . The reaction$ mixture was then heated at $25^{\circ} \mathrm{C}$ under stirring. In order to follow the progress of the reaction, aliquots $(0.1 \mathrm{~mL})$ could be taken at defined times, filtered through Celite with a $\mathrm{CH}_{2} \mathrm{Cl}_{2}$ wash (3 $\left.\mathrm{mL}\right)$, evaporated under vacuum and analysed by ${ }^{1} \mathrm{H}$ NMR. After 0.5 hour, water (2 eq.) was added and the reaction was stirred for an additional 0.5 hour. The resulting mixture was filtered over $\mathrm{MgSO}_{4}$ and evaporated under vacuum. The crude product was then directly purified by flash chromatography or by preparative TLC

Volatile compounds were isolated as the 2,4dinitrophenylhydrazone adducts. After reaction, the crude product was filtered over $\mathrm{MgSO}_{4}$ and diluted with ethanol (1 $\mathrm{mL}$ ). The resulting solution reacted with $0.5 \mathrm{~mL}$ of Brady's reagent [solution of 2,4-dinitrophenylhydrazine $(0.3 \mathrm{~g}), \mathrm{H}_{2} \mathrm{O}$ $(1.5 \mathrm{~mL})$, ethanol $(5 \mathrm{~mL})$ and $\mathrm{H}_{2} \mathrm{SO}_{4}$ conc $\left.(1 \mathrm{~mL})\right]$ during 30 minutes under vigorous stirring. The resulting orange precipitate was filtered through a filter paper, washed with ethanol $(10 \mathrm{~mL})$ and dried under vacuum.

\section{Computational details}

Computations were performed with methods of Density Functional Theory, i.e the PBE ${ }^{[18]}$ GGA functional implemented in the Amsterdam Density Functional package (ADF2013 ${ }^{[19]}$ version) and augmented with Grimme's DFT$\mathrm{D} 3(\mathrm{BJ})^{[20]}$ implementation of dispersion with a BeckeJohnson (BJ) damping function. Scalar relativistic corrections with the Zeroth Order Regular Approximation ${ }^{[21]}$ were applied with ad hoc all-electron $(A E)$ basis sets consisting of polarized triple- $\zeta$ (TZP) Slater type orbitals. Geometry optimization by energy gradient minimization was carried out in all cases with a numerical grid accuracy comprised between 4.5 and 8 , an energy gradient convergence criterion of $10^{-3}$ au and a very tight SCF convergence criterion. Vibrational modes were computed to verify that the optimized geometries were related to energy minima not considering residual modes comprised between 0 and $90 \mathrm{icm}^{-1}$. Representations of molecular structures and isosurfaces were produced with ADFview 2013.

\section{Acknowledgements}

The University of Lille 1 and Région Nord-Pas de Calais are acknowledged for PhD fellowships (Y. C. and V. R.). The CNRS, the Chevreul Institute (FR 2638), the Ministère de l'Enseignement Supérieur et de la Recherche, the LABEX 
Chimie des Systèmes Complexes (Strasbourg), the Région Nord - Pas de Calais and the FEDER are acknowledged for supporting and funding partially this work. Mrs C. Méliet and C. Delabre (UCCS) are thanked for GC and GC-MS analyses. Mrs N. Duhal and C. Lenglart (CUMA, Univ. of Lille) are thanked for HRMS analyses.

Keywords: iridium • metallacycles $\cdot$ hydrosilylation $•$ esters $•$ aldehydes.

[1] a) F. Agbossou, J.-F. Carpentier, A. Mortreux, Chem. Rev. 1995, 95, 2485-2506; b) G. T. Whiteker, C. J. Cobley, Top. Organomet. Chem. 2012, 42, 35-46; c) M. Vilches-Herrera, L. Domke, Armin Börner, ACS Catal. 2014, 4, 1706-1724.

[2] a) D. Romano, R. Villa, F. Molinari, ChemCatChem 2012, 4, 739-749; b) S. E. Davis, M. S. Ide, R. J. Davis, Green Chem. 2013, 15, 17-45.

[3] a) Modern Reduction Methods (Eds.: P. G. Andersson, I. J. Munslow) Wiley, New York, 2008; b) P. A. Dub, T. Ikariya, ACS Catal. 2012, 2 1718-1741; c) J. March in Advanced Organic Chemistry: Reactions, Mechanisms and Structures, Seventh Edition, Wiley-VCH, New-York, USA, 2013.

[4] a) L. I. Zakharkin, I. M. Khorlina, Tetrahedron Lett. 1962, 619-620; b) N. Z. Burns, P. S. Baran, R. W. Hoffmann, Angew. Chem. Int. Ed. 2009 , 48, 2854-2867; c) D. Webb, T. F. Jamison, Org. Lett. 2012, 14, 568 571 and references therein.

[5] a) B. Marciniec, H. Maciejewski, C. Pietraszuk, P. Pawluć in Hydrosilylation: A Comprehensive Review on Recent Advances, (Ed. B Marciniec), Springer, Heidelberg, 2009; b) D. Addis, S. Das, K. Junge, M. Beller, Angew. Chem. Int. Ed. 2011, 50, 6004-6011; c) K. Revunova, G. I. Nikonov, Dalton Trans. 2015, 44, 840-866.

[6] Hydrosilylation of esters to alcohols: a) S. C. Berk, K. A. Kreutzer, S. L. Buchwald, J. Am. Chem. Soc. 1991, 113, 5093-5095; b) S. C. Berk, S. L. Buchwald, J. Org. Chem. 1992, 57, 3751-3753; c) D. J. Parks, W. E. Piers, J. Am. Chem. Soc. 1996, 118, 9440-9441; d) H. Mimoun, J. Org. Chem. 1999, 64, 2582-2589; e) T. Ohta, M. Kamiya, M. Nobutomo, K. Kusui, I. Furukawa, Bull. Chem. Soc. Jpn. 2005, 78, 1856-1861; f) A. C. Fernandes, C. C. Romão, J. Mol. Cat. A: Chem. 2006, 253, 96-98; g) S. Das, K. Möller, K. Junge, M. Beller, Chem. Eur. J. 2011, 17, 7414-7417; h) L. Pehlivan, E. Métay, S. Laval, W. Dayoub, D. Delbrayelle, G. Mignani, M. Lemaire, Eur. J. Org. Chem. 2011, 7400-7406; i) D. Bézier, G. T. Venkanna, L. C. Misal Castro, J. Zheng, T. Roisnel, J.-B. Sortais C. Darcel, Adv. Synth. Catal. 2012, 354, 1879-1884; k) K. Junge, B. Wendt, S. Zhou, M. Beller, Eur. J. Org. Chem. 2013, 2061-2065; I) O. O. Kovalenko, H. Adolfsson, Chem. Eur. J. 2015, 21, 2785-2788.

[7] Hydrosilylation of esters to ethers: a) Z. Mao, B. T. Gregg, A. R. Cutler, J. Am. Chem. Soc. 1995, 117, 10139-10140; b) M. C. Hansen, X Verdaguer, S. L. Buchwald, J. Org. Chem. 1998, 63, 2360-2361; c) N. Sakai, T. Moriya, T. Konakahara, J. Org. Chem. 2007, 72, 5920-5922 d) S. Das, Y. Li, K. Junge, M. Beller, Chem. Commun. 2012, 48, 10742-10744.

[8] a) M. Igarashi, R. Mizuno, T. Fuchikami, Tetrahedron Lett. 2001, 42, 2149-2151; b) J. Nakanishi, H. Tatamidani, Y. Fukumoto, N. Chatani, Synlett 2006, 17, 869-872; c) D. J. Parks, J. M. Blackwell, W. E. Piers, J. Org. Chem. 2000, 65, 3090-3098; d) C. Cheng, M. Brookhart,
Angew. Chem. Int. Ed. 2012, 51, 9422-9424; e) H. Li, L. C. Misal Castro, J. Zheng, T. Roisnel, V. Dorcet, J.-B. Sortais, C. Darcel, Angew. Chem. Int. Ed. 2013, 52, 8045-8049.

[9] a) K. Matsubara, T. Iura, T. Maki, H. Nagashima, J. Org. Chem. 2002 67, 4985-4988; b) H. Nagashima, Y. Kubo, M. Kawamura, T. Nishikata Y. Motoyama, Tetrahedron 2011, 67, 7667-7672; c) H. Nagashima, Synlett. 2015, 26, 866-890.

[10] a) W. Iali, F. La Paglia, X.-F. Le Goff, D. Sredojevic, M. Pfeffer, J.-P Djukic, Chem. Commun. 2012, 48, 10310-10312; b) Y. Corre, W. Iali, M. Hamdaoui, X. Trivelli, J.-P. Djukic, F. Agbossou-Niedercorn, C Michon, Catal. Sci. Technol. 2015, 5, 1452-1458; c) C. Michon, K. MacIntyre, Y. Corre, F. Agbossou-Niedercorn, ChemCatChem 2016, 8 , 1755-1762

[11] a) C. T. Chang, C. L. Chen, Y. H. Liu, S. M. Peng, P. T. Chou, S. T. Liu, Inorg. Chem. 2006, 45, 7590-7592; b) C. C. Chang, B. S. Liao, S. T. Liu, Synlett 2007, 18, 283-287.

[12] Acetals resulting from the hydrosilylation of esters $\mathbf{3 f}$ and $\mathbf{3 q}$ could not be hydrolyzed through the addition of water. Hydrolysis attempts by addition of $13 \mathrm{eq}$. of $\mathrm{HCl}\left(2 \mathrm{M}\right.$ solution in $\mathrm{Et}_{2} \mathrm{O}$ ) to the crude reaction mixture didn't afford the related aldehydes after 15 hours of reaction at room temperature. Hydrolysis of the scheduled acetals using 13 eq. of $\mathrm{NaOH}$ (2M aq.) or $\mathrm{HCl}\left(2 \mathrm{M}\right.$ in $\left.\mathrm{Et}_{2} \mathrm{O}\right)$ and $\mathrm{THF}$ didn't work too after 15 hours of reaction at room temperature.

[13] M. Hamdaoui, M. Ney, V. Sarda, L. Karmazin, C. Bailly, N. Sieffert, S. Dohm, A. Hansen, S. Grimme, J.-P. Djukic, Organometallics 2016, in press, DOI: 10.1021/acs.organomet.6b00248.

[14] a) M. Iglesias, F. J. Fernández-Alvarez, L. A. Oro, ChemCatChem 2014 6, 2486-2489; b) T. T. Metsänen, P. Hrobárik, H. F. T. Klare, M. Kaupp, M. Oestreich, J. Am. Chem. Soc. 2014, 136, 6912-6915; c) W. Wang, P. Gu, Y. Wang, H. Wei, Organometallics 2014, 33, 847-857; d) M. Iglesias, P. J. Sanz-Miguel, V. Polo, F. J. Fernández-Alvarez, J. J Pérez-Torrente, L. A. Oro, Chem. Eur. J. 2013, 19, 17559-17566; e) J. Yang, P. S. White, M. Brookhart, J. Am. Chem. Soc. 2008, 130, 1750917518.

[15] a) C. Scheeren, F. Maasarani, A. Hijazi, J.-P. Djukic, M. Pfeffer, S. D. Zaric, X.-F. LeGoff, L. Ricard, Organometallics 2007, 26, 3336-3345; b) Y. Hu, L. Li, A. P. Shaw, J. R. Norton, W. Sattler, Y. Rong, Organometallics 2012, 31, 5058-5064.

[16] a) J. B. Lambert, S. Zhang, C. L. Stern, J. C. Huffman, Science 1993 260, 1917-1918; b) S. J. Connelly, W. Kaminsky, D. M. Heinekey, Organometallics 2013, 32, 7478-7481.

[17] V. R. Naidu, S. Ni, J. Franzén, ChemCatChem 2015, 7, 1896-1905.

[18] J. P. Perdew, K. Burke, M. Ernzerhof, Phys. Rev. Lett. 1996, 77, 38653868 .

[19] K. Vanka, M. S. W. Chan, C. C. Pye, T. Ziegler, Organometallics 2000 , 19, 1841-1849.

[20] a) S. Grimme, S. Ehrlich, L. Goerigk, J. Comp. Chem. 2011, 32, 14561465 ; b) S. Grimme, Wiley Interdisciplinary Reviews: Computational Molecular Science 2011, 1, 211-228.

[21] a) E. van Lenthe, E.-J. Baerends, J. G. Snijders, J. Chem. Phys. 1993 99, 4597-4610; b) E. van Lenthe, E.-J. Baerends, J. G. Snijders, J. Chem. Phys. 1994, 101, 9783-9792; c) E. van Lenthe, A. Ehlers, E.-J. Baerends, J. Chem. Phys. 1999, 110, 8943-8953. 
